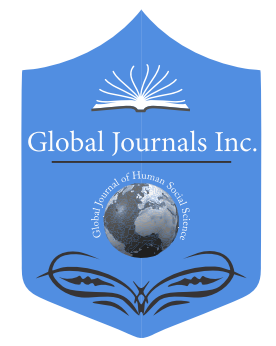

\title{
Timbre in the Musical Performance as a Result of Audio-Mental Operations
}

By Ana Szilagyi Abstract- The aim of this paper is to reveal the relationship between the timbre, i.e. sound quality, obtained by an instrumentalist when playing a music piece, and the role of the hearing, listening, and other musical specific mental operations that take place in the brain of the instrumentalist during the performance, with the focus on the classical music, which depends in the most cases on the score. The timbre is a characteristic of every instrument or voice that makes their tone unique. It is given by the different sound components (partials) with different frequencies and amplitudes. The number and the amplitude of the partials are different from instrument to instrument; they depend on the construction of the instrument and on the art of playing, the last being the point in this article. It is known that timbre has an emotional impact on the perception. Its semantic features are represented through descriptors as: dark, bright, round, dull, dry, harsh, etc. that have to be created by the performers, in order to affect the auditory. Thus, they have to possess a good technique, able to get different timbres. Although, the technique has to be subordinated to the capacity of hearing in advance the sound with all its features: pitch, duration, intensity and timbre.

GJHSS-A Classification: FOR Code: 190409

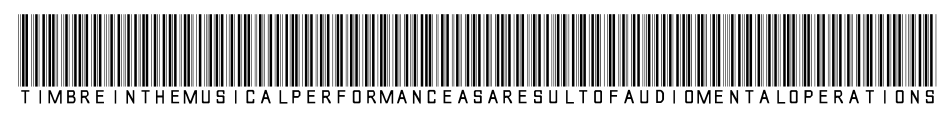

Strictly as per the compliance and regulations of:

(c) 2021. Ana Szilagyi. This research/review article is distributed under the terms of the Attribution-NonCommercial-NoDerivatives 4.0 International (CC BY-NC-ND 4.0). You must give appropriate credit to authors and reference this article if parts of the article are reproduced in any manner. Applicable licensing terms are at https://creativecommons.org/licenses/by-nc-nd/4.0/. 


\title{
Timbre in the Musical Performance as a Result of Audio-Mental Operations
}

\author{
Ana Szilagyi
}

Abstract- The aim of this paper is to reveal the relationship between the timbre, i.e. sound quality, obtained by an instrumentalist when playing a music piece, and the role of the hearing, listening, and other musical specific mental operations that take place in the brain of the instrumentalist during the performance, with the focus on the classical music, which depends in the most cases on the score. The timbre is a characteristic of every instrument or voice that makes their tone unique. It is given by the different sound components (partials) with different frequencies and amplitudes. The number and the amplitude of the partials are different from instrument to instrument; they depend on the construction of the instrument and on the art of playing, the last being the point in this article. It is known that timbre has an emotional impact on the perception. Its semantic features are represented through descriptors as: dark, bright, round, dull, $\mathrm{dry}$, harsh, etc. that have to be created by the performers, in order to affect the auditory. Thus, they have to possess a good technique, able to get different timbres. Although, the technique has to be subordinated to the capacity of hearing in advance the sound with all its features: pitch, duration, intensity and timbre. The excessive attention of the performers from the pitch and duration that are exactly notated in the score has to be turned to the intensity and timbre that are less notated. Therefore, the audio-mental operations (the term belongs to piano teachers Ana Pitiş and loana Minei), both of the performers and listeners as part of music cognition, are discussed here. The decoding of the music information from the score and the sending of it to the auditory together with the regarding of the music as a language were be also approached.

\section{INTRODUCTION}

T his paper focuses on the timbre as a sound quality that has to be formed by the performer for getting a performance that affects the auditory. Therefore, the instrumentalist has not to reduce the play on the physical qualities of the instrument, but to create an expressive and emotional timbre with help of technical means. As Ştefana-Graţiela Negruţiu says, the sound quality, bearer of sensations, significance and artistic emotions, has to be physically and mentally prepared by the performer [1]. These technical means for each instrument has to be further subordinated to audiomental operations that take place in the brain of the performer (in the daily practice, rehearsal or stage performance). The term "audio-mental operations" [2] belongs to the piano teachers Ana Pitiş and Ioana Minei

Author: Department of Instrumental and Vocal Pedagogy, Richard Wagner Conservatory Vienna, Austria.

e-mail: anaszilagyi71@gmail.com and refers to the complex process of hearing and thinking of music before and during playing it, what I shall expose in details.

The attention of students is generally more concentrated on the pitch and duration - Charise Hastings calls these fixed qualities [3] -, neglecting the other two qualities of the sound, intensity and timbre that are in a close connection: the intensity affects the timbre, an important fact that has to be stressed in the performance. While pitch and duration are exactly notated in the score, intensity and timbre are generally notated, mostly with words describing them. So these have to be related to pitch and duration. As the piano professors Ana Pitiş and loana Minei said, the sound has to be heard in advance with all its four qualities, while reading the score, before playing it. The two authors named this anticipative way of hearing "inner hearing" [2]. Regarding their opinion, hearing in advance the sound with all its features has as result an enriched piano sound, with differences in dynamics, timbre, slow tempo oscillations, and expressivity [4]. This could be useful for all instruments. Strings, wind instruments or human voice are however able to influence the sound over time through periodic pitch oscillations named vibrato or through the manipulating of the sound intensity. From this point of view the piano sound is poorer and maybe for this reason many researches have explored the piano timbre; getting a good timbre were a challenge for a pianist.

The timbre is in the same time a physical dimension, which is given by its harmonic spectrum based on different frequencies, and a psychological dimension with its quality to trigger emotions in the listeners. In this way Hugues Dufourt says about the timbre that it "welds physical acoustics to psychological acoustics" [5]. Verbal expressions - descriptors - are characteristic for timbres, as round, dark, clear, bright, dry, etc. The fact that the sonority of a certain instrument triggers a specific emotion might be culturally conditioned, like Christian Tronhjem supposes [6].

Timbre has also semantic features. Every sonority could have other meaning, significance. This closes music to the spoken language [7]. Like in the language, music sends information and the listener has to decode it. Thus the performer has to send a coherent message, delimiting the musical phrases, stressing the important element of them. This supposes besides audio operations also mental operations from the 
performers, specific for the musical thinking and imagery that I shall treat here.

In this paper the timbre will be regarded as a physical and psychological quality. Further, the technical means used by the performer will discussed, as well as the audio-mental operations that have an important role in order to obtain a beautiful timbre that can affect the auditory.

\section{TIMBRE \\ a) Timbre as an Acoustical Parameter in the Performance}

The timbre is the result of the interaction of harmonic and inharmonic components (partials) of a sound that we perceive as sound color. The partials form the harmonic spectrum that has different frequencies with different amplitudes. The presence, strength, and mix of partials vary from performer to performer, even if two pianists play the same piece with the same pitches and similar dynamic levels [8]. Therefore, timbre is one element that makes the difference between performers. Each instrument favors certain partials (formants), other partials being weak or absent. Further, the number of the frequencies and their amplitude vary over time (spectral envelope). Regarding instrumental spectra, a degree of noise is present within, which depends on the physical system of sound production, as the breath of a wind player or the scraping of the bow on the string [9]. All these characteristics, together with the attack transients "noise-like" [9], present at the beginning of the sound, make every instrumental timbre unique. Timbre also depends on the intensity and on the register one plays (low, middle or high register): a louder tone has more harmonics; a higher tone has fewer harmonics that could be perceived by our ear. Knowing these physical characteristics of the own instrument, the performer has to create himself an individual timbre, using specific technical means. For example, the violinist can play with more or less bow pressure, or using the whole bow or a certain side of it; moreover the bowing place is important, as well as the vibrato that can be larger or closer, fast or slow. The same note played with the same intensity on two different strings has two different timbres. For the wind instruments the pressure of blew air, the lips position in combination with the keys get different timbres. The piano can obtain different sound effects through the pianistic touch (with faster velocity or with lower velocity) [10], with or without different pedals. The choice of these ways of playing have to be in connection with the indications in the score referring to other parameters as pitch, duration, intensity, register, texture, structure, form, according to the style, and character of the piece.

\section{b) Timbre as a Psychological Dimension}

It is known that timbres have emotional connotations. They are represented through descriptors as round, brilliant, dark, dry, metallic, shrill, etc. Timbres have a meaning or an emotion for the listener, so the performer is responsible to create a palette of timbres, as the painter a palette of colors. Creating different timbres with aesthetic and semantic features is to give a meaning to the performed music. This approached the music to the language. In this way, Stefan Koelsch writes that "decoding of both music and speech information requires a fine grained analysis of the spectral and temporal of an acoustic information" and that "Both speech and music perception involve premotor coding and both music and language give rise to affective processes" [7].

Timbral changes as attack and spectral content have a bigger emotional effect than the change of other parameters (melody, tempo or harmony) [11]. This could be the result of our habit with the voice timbre in the spoken language, which could have different expressions [11], [6]. The association of the musical timbre with the timbre of the spoken language could be an incentive for the performer in order to organize his playing as a speech.

\section{ili. Audio-Mental Operations}

This term was used by the piano teachers Ana Pitiş and loana Minei in their Treatise of Piano Art, published in 1982 by Editura Muzicală Bucharest. The treatise explains the art of piano playing in an interdisciplinary way, with the help of music theory, psychoacoustics, cybernetics, linguistics, and biomechanics. The aim is to obtain a quality of piano sonority that implies the timbre, but also an intellectual work. In the centre of their theory there is the inner hearing. The inner hearing refers to hearing in advance while reading a score and only then playing it. While seeing the text signs of a score the performer imagines the sounds with their duration, dynamics, tempo and the character [12]. The score information is in this way processed in the cortex of the performer after musical laws and only then concretized in the piano sound. Therefore, sounds are no longer reduced on their isolated pitches and durations, but interrelated; they appear enriched to the listener, with intensity, timbre and expression, even for a mechanical instrument as piano. Arabela Bravo and Philip Fine also point out the analysis of the score that expert musicians do seeing a score. This analysis implies "hearing the music internally and understanding its structure, therefore creating an association between seeing and hearing." [13]. Another aspect of this theory regards the technique, the motor part that is subordinated to the auditory command. In other words, the attention turns from the technical difficulties to the inner hearing that guides one to the right movements and energies in order to get the ideal represented sonority. Regarding the technique Viktoria Tzotzkova similarly writes that pianists can 
adjust the keystoke to different performance conditions; she supposes that "skilled pianists come »to feel« the sound through the keyboard and pedals" [8]. After listening experiences with classical music, knowing the musical laws of classic music (how music is constructed, how the parameters interact) the inner hearing leads to the differential technical means that I have meant in the previous chapter. According with this statement, specialists in music psychology and neuroscience take into account the "inner ear": "... an expert pianist reading a piano score hears the notation as an auditory representation in his or her (inner) ear and at the same time may feel the sound as a kinesthetic representation in his or her fingers." [14]. The two piano teachers speak besides anticipative hearing about "control hearing". According to them, the last works on the feedback from the cybernetics [4]: the performer listens to how he/she is playing, whether the result corresponds to the ideal sonority represented in advance and rectifies the quality of the sound in a new performance [12].

As we have seen, the audio-operations are not reduced on the sensory ones. They involve other centers on the cortex, fact that leads to associations [2]. As result, the score will be processed using further mental operations. The audio and mental operations take place in the same time. The two authors speak about a simple auditory perception without associations perceiving the sound as high, loud or short, and about a complex auditory analysis that involves associations. The last can be functional and semantic. The functional auditory analysis strictly refers to the musical material, syntax and functions of musical elements. The semantic auditory analysis goes over the music, creating visual images, space, movement (for example dance or march's rhythmus), dispositions, psychological characters, life experiences, dispositions, ideas etc. At that level is the timbre processed and described as poetical, sharp, warm etc. [2].

More recent researches about the music process in the brain similarly describe the processing of music information. The primarly auditory cortex processes fundamental elements as frequencies of tones and loudness. Secondary and tertiary auditory cortex process more complex stimulus features: the secondary auditory cortex identifies harmonic, melodic or rhythmic patterns and the tertiary auditory cortex processes complex sound patterns in a piece of music [14].

Here is the place to mention that the processing of musical information takes place in a similar way by the performer and by the auditory, if both are accustomed with the same genre of music. The listening to music plays an important role. As Marcus Pearce and Martin Rohrmeier wrote, "Processing all of these levels of structure requires learning of relevant relations between musical elements and the ability to maintain in memory features of specific musical pieces, musical cues, and schemata, as well as generalized properties of musical styles. In addition, musical structure generates patterns of salience that guide attention towards significant events in time." [15]. Revealing significant events in time, preparing them by the performer means making the music more expressive and captivating.

\section{The Influence of Audio-Mental Operations on the Timbre}

Listening to classical music, especially vocal and symphonic music, increases the ability of the performer to create a big variety of timbres, which bear emotion and significance. Voices and wind instruments are a good model, because they need a breath that is closer to the human emotions. Moreover, the breath normally corresponds to the musical phrasing.

Turning the attention from the pitch to timbre, the performer is able to obtain a good sonority. The pitches are no longer seen as isolated notes, but in a close connection. The graphic notes representing pitches and durations have to be treated as frequencies, i.e. as vibrations per second. Therefore, the listening plays an important role. By the instruments which produce low frequencies one has to listen to the vibrations. Negruţiu speaks about the spatial spherical and ovoid movements of a vibrating string that depend on the intensity. Regarding to this aspect she writes that a loud tone has not to be felt as pressed down on a string, but as a large vibrating string [1]. Giving to every frequency a color through relating it to the previous and next frequency, and including each frequency to a larger context, means to create a structure with a significance, which goes over the physical aspect and enters the psychological domain. Thus, performers can create fine, different timbres modifying in an imperceptible way the intensity from one to other sound [12]. In this way, the performer gives sense to a frequency relation, the upper tone being a bit louder than the lower one. In order to equilibrate the content of harmonics of every musical sound (the lower sounds have more harmonics than the higher ones, giving the impression of being louder), the performers have to dynamically (as intensity) differentiate them, as the conductor Celibidache said [2]; basing on this statement, the composer Ştefan Niculescu concluded that going up on the pitch scale the performers have to increase the intensity and going down on the pitch scale they have to decrease it [2]. This is one important element that contributes to obtain a beautiful timbre, connecting the pitch with the intensity.

Bibiana Bregoglio and Didier Guigue concluded after their researches that the sonority is influenced 
by the interpretative choises regarding variations in dynamics, timbre, pianistic touch, pedals and timing [10]. We would add that these decisions are the fruit of the audio-mental representations of the score.

Thinking the music means to order the musical elements after musical rules: to understand the syntax, i.e. the more important note in a phrase, to stress a rhythmic formula in a grouping or to take into account the similarities. Regarding the relation between the similarities in the music construction and the emotions, Eckart Altenmüller wrote "The brain rewards the experience of an ordered construction with positive emotions, because the recognition of similarities is a way for understanding the world..." [16]. The musical material (the sounds) has to be good organized and structured after musical rules and cognition laws, similar to the spoken language, in order to send a message.

\section{Conclusions}

The music performance is a complex process, which requires cognitive, motor and emotional skills. The timbre involves all these skills. We have seen that timbre (sonority) has besides physical properties psychological ones, which depend on the sound quality. The performer has to make a captivating, impressive, emotional sonority giving significance to a musical score through technical means that are subordinated to audiomental operations. The audio-mental operations refer to the ability of the performer to hear and think in advance the music notated in the score. This supposes experience with music listening, knowledge of music theory in order to understand the rules the music is made up, acoustics, and music psychology in order to understand how the sound quality emotionally affects the listener.

As timbre is a bearer of emotion and significance, the priority of the performer is to obtain a good sonority and to give a sense to the music, having as starting point an audio-mental representation of the score. The information taken from the score and filtered through the intellect and the personality of the performer has as result an expressive sound, with an impact on the auditory.

\section{References Références Referencias}

1. Negruţiu, Ştefana-Graţiela. 2007. Fenomene polare in arta interpretării muzicale. Referiri speciale la arta violonistică. Timişoara: Editura Marineasa.

2. Pitiş, Ana; Minei, Ioana. 1982. Tratat de artă pianistică. Bucureşti: Editura Muzicală.

3. Hastings, Charise. 2011. "How expert pianists interpret scores: A hermeneutical model of learning", Proceedings of the International Symposium on Performance Science 2011, pp. 369-374.
4. Szilágyi, Ana. 2015. "A Theory of Piano Interpretation based on Cybernetics", New Sound 46, II/2015, pp. 107-115.

5. Dufourt, Hugues. 2014. La musique spectrale. Une révolution épistémologique. Editions Delatour France.

6. Tronhjem, Christian. 2019. "Sounding Emotional: How Timbre Choices Affect Emotions in Music", The Sound of Al, Melodrive, Feb. 21, 2019.

7. Koelsch, Stefan. 2011. "Toward a neural basis of music perception - a review and updated model", frontiers in Psychology 2011, v.2, p.110.

8. Tzotzkova, Victoria. 2011. "Exploring real-time sonic adjustements in the performance of notated music: Morton Feldman, space acoustics, and the variable timbres of piano sound", Proceedings of the International Symposium on Performance Science 2011, pp. 565-570.

9. Fineberg, Joshua. 2000. "Guide to the Basic Concepts and Techniques of Spectral Music", Contemporary Music Review, Vol. 19, Part 2, pp. 81-113.

10. Bregoglio, Bibiana; Guigue, Didier. 2018. "Analysis of the Sonority: an Approach based upon the Performance", Proceedings of the $11^{\text {th }}$ International Conference of Students of Systematic Musicology, 2018, pp. 10-14.

11. Hailstone, Julia C.; Omar, Rohani; Henley, Susie M.D.; Frost, Chris; Kenward, Michael G., Warren, Jason D. 2009. "It's not what you play, it's how you play it: Timbre affects perception of emotion in music", The Quaterly Journal of Expermental Psychology, 62(1), pp. 2141-2155.

12. Pitiş, Ana; Minei, loana. 1997. Teoria comportamentului pianistic, Bucureşti: Editura Sfântul Gheorghe-Vechi.

13. Bravo, Anabela; Fine, Philip. 2009. "Studying a score silently: What benefits can it bring to performance?, Proceedings of the International Symposium on Performance Science 2009, pp. 243-248.

14. Altenmüller, Eckart O.; Bangert, Marc W.; Liebert, Gundhild; Gruhn, Wilfried. 2000. „Mozart in Us: How the Brain Processes Music", presented as the Richard Lederman Lecture at the Seventeenth Annual Symposium on Medical Problems of Musicians and Dancers, Aspen, Colorado, June 1999, Medical Problems of Performing Artists, September 2000, pp. 99-106.

15. Pearce, Marcus; Rohrmeier, Martin. 2021. "Music Cognition and the Cognitive Sciences". Topics in cognitive sciences, Volume 4, Issue 4, Oct. 2021, pp. 468-484.

16. Altenmüller, Eckart. 2018. Vom Neandertal in die Philharmonie. Warum der Mensch ohne Musik nicht leben kann, Berlin: Springer-Verlag. 